\title{
ПРИРОДНОЕ РЕДАКТИРОВАНИЕ РНК С ЗАМЕНОЙ АДЕНОЗИНА НА ИНОЗИН МОЖЕТ УЧАСТВОВАТЬ В ПАТОГЕНЕЗЕ БОЛЕЗНЕЙ ЧЕЛОВЕКА
}

\author{
А. А. Ключникова $\bowtie$, С. А. Мошковский
}

Научно-исследовательский институт биомедицинской химии имени В. Н. Ореховича, Москва, Россия

Российский национальный исследовательский медицинский университет имени Н. И. Пирогова, Москва, Россия

\begin{abstract}
Редактирование РНК с заменой аденина на инозин является наиболее распространенным природным механизмом постранскрипционной модификации у разных многоклеточных организмов, включая позвоночных, и катализируется ферментами семейства PHK-зависимых аденозиндезаминаз ADAR. Недавние исследования с использованием высокопроизводительного секвенирования нуклеиновых кислот позволили выявить тысячи участков такого редактирования и у человека, однако функция многих из них остается не до конца ясной. Мы хотим привлечь внимание клиницистов и специалистов по биомедицине к ADAR-опосредованному редактированию мPHK и его возможному участию в развитии болезней нервной системы, противовирусных иммунных реакций и злокачественных опухолей.
\end{abstract}

Ключевые слова: РНК-зависимая аденозиндезаминаза (ADAR), редактирование РHK, иммунитет, злокачественная опухоль, нейродегенеративные заболевания

Финансирование: работа выполнена в рамках Программы фундаментальных научных исследований государственных академий наук на $2013-2020$ гг.

Информация о вкладе авторов: оба автора в равной степени участвовали в написании текста статьи.

$\triangle$ Для корреспонденции: Анна Алексеевна Ключникова

ул. Погодинская, д. 10, стр. 8, г. Москва, 119121; a.kliuchnikova@gmail.com

Статья получена: 13.08.2018 Статья принята к печати: 06.04.2019 Опубликована онлайн: 16.04.2019

DOI: $10.24075 /$ vrgmu.2019.028

\section{ADENOSINE-TO-INOSINE RNA EDITING MAY BE IMPLICATED IN HUMAN PATHOGENESIS}

Kliuchnikova AA $\square$, Moshkovskii SA

Institute of Biomedical Chemistry, Moscow, Russia

Pirogov Russian National Research Medical University, Moscow, Russia

\begin{abstract}
Adenosine-to-inosine (A-to-I) RNA editing is a common mechanism of post-transcriptional modification in many metazoans including vertebrates; the process is catalyzed by adenosine deaminases acting on RNA (ADARs). Using high-throughput sequencing technologies resulted in finding thousands of RNA editing sites throughout the human transcriptome however, their functions are still poorly understood. The aim of this brief review is to draw attention of clinicians and biomedical researchers to ADAR-mediated RNA editing phenomenon and its possible implication in development of neuropathologies, antiviral immune responses and cancer.
\end{abstract}

Keywords: RNA-specific adenosine deaminase (ADAR), RNA editing, immune resistance, malignant tumour, neurodegenerative disease

Funding: the work was performed within The Programme for fundamental scientific research of state science academies for $2013-2020$.

Author contribution: both authors have contributed equally to manuscript writing.

$\bowtie$ Correspondence should be addressed: Anna A. Kliuchnikova

Pogodinskaya 10, bld. 8, Moscow, 119121; a.kliuchnikova@gmail.com

Received: 13.08.2018 Accepted: 06.04.2019 Published online: 16.04.2019

DOI: 10.24075/brsmu.2019.028

Редактирование РНК — это один из посттранскрипционных механизмов изменения химической структуры нуклеотидов. Сразу отметим, что здесь мы будем говорить о редактировании РНК как о естественном явлении, которое не следует путать с вмешательством человека в последовательность нуклеиновых кислот, например, с использованием бактериальных систем CRISPR/Cas. Наиболее распространенным видом такого природного редактирования является замена аденина на инозин, опосредованная ферментами семейства РНК-зависимых аденозиндезаминаз (ADAR). Процесс называется редактированием, потому что такие изменения во многих случаях ведут к изменению информационного содержания PHK.

У человека известно три гена ADAR, продукты двух из которых (ген adar/белок ADAR1, ген adarb1/белок ADAR2) обладают ферментативной активностью в отношении PHK, а третий (adarb2/ADAR3) - ингибирует такую активность [1]. Активные ферменты ADAR обладают способностью дезаминировать остатки аденозина в PHК, предпочтительно, в двухцепочечных участках. Свойства отредактированной таким образом молекулы PHК меняются. Если реакция происходит в кодирующей части мРНК, то может перекодироваться белок, поскольку инозин воспринимается в рибосоме как гуанозин [2].

Неизвестный до 1987 г. процесс редактирования PHK аденозиндезаминазами, как было показано в последние годы, широко распространен в геноме большинства животных, и с ним ассоциировано несколько функций. Так, у некоторых первичноротых, в частности, у головоногих моллюсков, процесс перекодирования генома и протеома выражен в большей степени, чем у беспозвоночных, и, как предполагают, обеспечивает их молекулярную пластичность при изменении условий окружающей среды и, вместе с тем, эволюционный консерватизм [3].

Известен процесс редактирования РНК описанного типа и у млекопитающих. Недавно проведенная большая работа, в которой в масштабах транскриптомов 
исчерпывающе исследовали этот процесс, показала существование более 20000 сайтов редактирования в транскриптомах человека и мыши. Из них более 2000 у человека кодировали аминокислотные замены [1]. Разнообразие редактированных участков в транскриптоме получило название «эдитом РНК» по аналогии с другими молекулярными «омами».

Функция редактирования РНК такого типа до недавнего времени оставалась неясной. Однако с помощью нокаутов соответствующих генов, которые имели выраженное действие на здоровье грызунов, включая летальность, показано, что активность ADAR1 связана преимущественно с иммунитетом, a ADAR2 регулирует передачу сигнала и возбудимость в центральной нервной системе [4]. ADAR редактируют очень разнообразные субстраты, которые роднит только наличие двухцепочечной РНК. Это матричные, короткие и длинные некодирующие PHК, а также вирусные PHК. Масштаб явления осознан лишь в последнее время, и в связи с его сложностью знания о функциях такого редактирования в разных объектах накапливаются медленно.

Столкнувшись с феноменом естественного редактирования PHK на уровне протеома человека и экспериментальных животных, мы хотим познакомить читателей с этим явлением, поскольку оно может вносить вклад в развитие противовирусных иммунных реакций, участвовать в развитии болезней нервной системы, а также злокачественных опухолей.

\section{Редактирование РНК в центральной нервной системе}

Редактирование PHК особенно активно в центральной нервной системе (ЦНС). Оно ассоциировано преимущественно с работой фермента ADAR2 [1]. Известно, что на белковом уровне такое редактирование вносит точечные замены в последовательность потенциалуправляемых ионных каналов и рецепторов, связанных с $\mathrm{G}$-белками. K хорошо изученным явлениям редактирования можно отнести внесение замены в глутаматные рецепторы групп GluK и GluA. Так, в норме при развитии нервной системы редактирование приводит к замене глутамина на аргинин в одной из субъединиц глутаматных рецепторов. Изменение одной аминокислоты на другую способствует избирательной блокаде входа кальция в клетку через канал. Дефектная субъединица, не подвергшаяся редактированию, пропускает ионы кальция. Нейроны с такой субъединицей подвержены «физиологической» эксайтотоксичности из-за повышения глутамата в синапсе. Как известно, такое явление может приводить к гибели нейронов и являться важным фактором развития некоторых нейродегенеративных расстройств, в частности, распространения спинальной нейродегенерации при боковом амиотрофическом склерозе [5]. Мутации в adarb1 приводят к эпилепсии и заболеваниям, связанным с дефектами нейронной пластичности, такими как аутизм и синдром Мартина-Белл [4]. Нокаут гена adarb1, кодирующего ADAR2, служит причиной возникновения у мышей неотредактированных глутаматных рецепторов и вызывает повышенное возбуждение в головном мозге в виде судорожных припадков, во взрослом возрасте несовместимых с жизнью.

\section{Редактирование РНК и противовирусный иммунитет}

Накоплены разрозненные сведения о том, что активность ADAR1, в отличие от ADAR2, тем или иным образом связана с иммунитетом, в том числе с ответом на заражение PHКсодержащими вирусами. Показано, что данный фермент может играть роль в механизмах защиты организма против вирусной инфекции и воспаления. Taк, ADAR1 редактирует PHK вируса гепатита C, препятствуя его репликации [6]. Кроме того, эта аденозиндезаминаза редактирует в большей степени вирус гриппа по сравнению с вирусом кори, и, с одной стороны, делает его нефункциональным, с другой стороны, может способствовать его мутагенезу и уклонению от иммунитета [7].

Интерферон 1-го типа, как известно, индуцирует ADAR1 в виде повышенного синтеза его длинного сплайс-варианта p150, но такая активность препятствует образованию стрессовых гранул против коревого вируса. Таким образом, в целом, считается, что этот фермент препятствует ответу клеток на вирус кори [8].

Миссенс-мутации, приводящие к аминокислотным заменам в ADAR1, уменьшают активность редактирования PHК и вызывают синдром Айкарди-Гутьерес, представляющий собой прогрессирующую энцефало- и интерферонопатию, которые имитируют вирусную инфекцию [9], что свидетельствует о вовлеченности ADAR1 в иммунный ответ.

\section{Редактирование РНK при злокачественных опухолях}

Недавние исследования, проведенные в ходе проекта The Cancer Genome Atlas (TCGA), способствовали систематизации данных и геномов, и транскриптомов многих типов опухолей [10]. С использованием результатов секвенирования этих и других данных были получены библиотеки событий редактирования. Было выявлено множество таких событий в образцах опухолей по сравнению с соответствующими нормальными тканями. Для большинства опухолевых тканей, например, при раке головы и шеи, молочной железы и щитовидной железы, был характерен повышенный уровень редактирования, что в значительной степени связано с избыточной экспрессией ADAR1 в опухолях [11].

Случаи редактирования РНК в клетках головного мозга учащаются с возрастом, но их количество может уменьшаться при глиобластоме [12]. События редактирования РНК могут способствовать опухолевой прогрессии подобно драйверным соматическим мутациям. Например, в экспериментах как in vitro, так и in vivo получены сведения о белке, играющем важную роль в клеточном росте и пролисерации благодаря поддержанию гомеостаза полиаминов в клетке. Изменение ингибитора антизима 1 (AZIN1) ферментом ADAR1 превращает серин в глицин в 367 положении. Отредактированный продукт имеет большее сродство к антизиму и индуцирует транслокацию AZIN1 из цитоплазмы в ядро, что приводит к более агрессивному поведению опухолей [13]. Таким образом, отредактированный белок может представлять потенциальную терапевтическую мишень.

Некоторые события редактирования могут выступать в качестве предиктивных маркеров и влиять на ответ при раковой терапии. Например, замена аргинина на глицин в 764 положении белка глутаматного рецептора GRIA2 и изолейцина на валин в 635 положении белка COG3, ответственном за связывание и транспорт везикул между аппаратом Гольджи и эндоплазматическим ретикулумом, повышает чувствительность к ингибиторам киназы митоген-активируемой протеинкиназы (mitogen-activated protein kinase kinase, или MAPKK) [14]. 


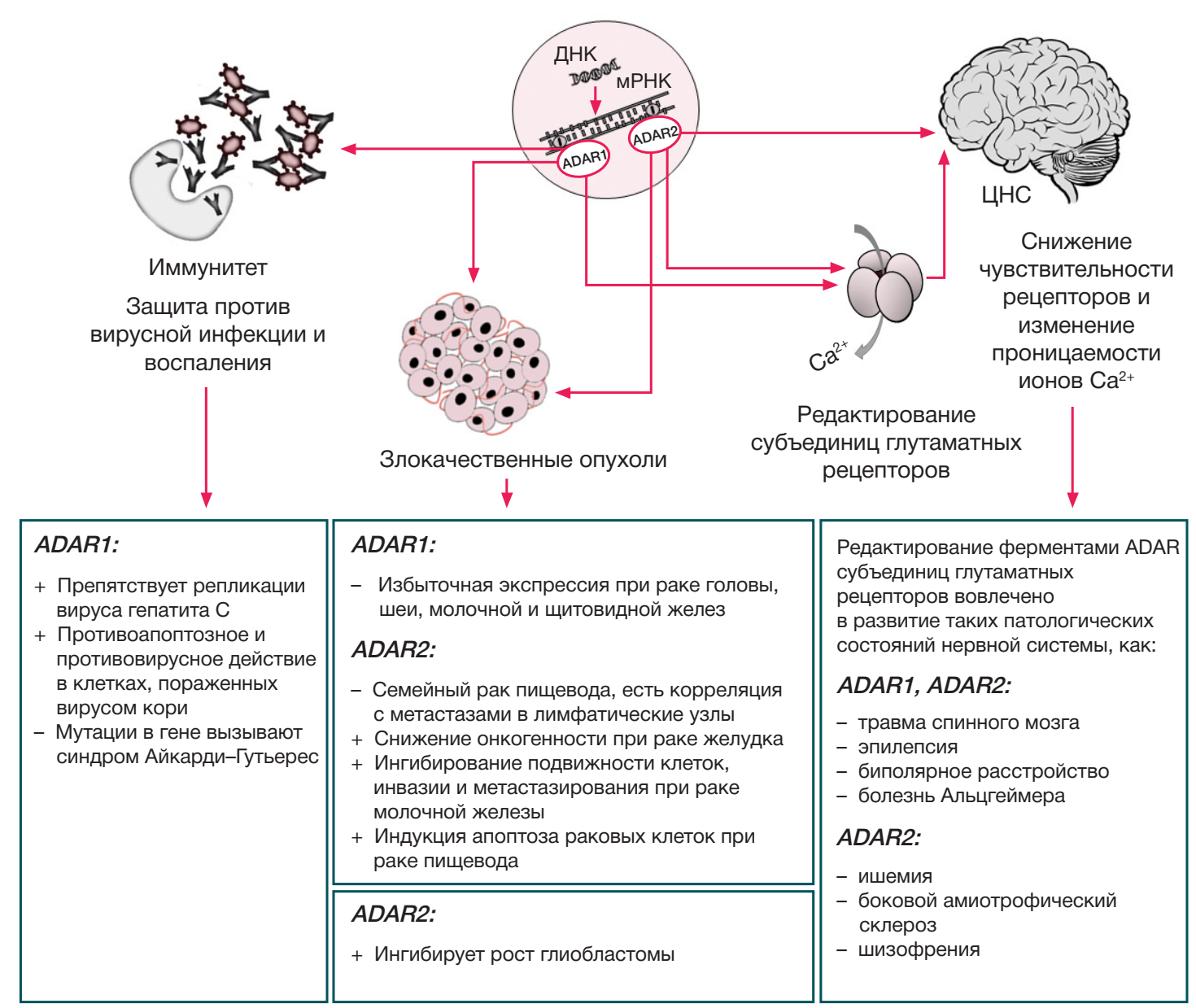

Рис. 1. Эффекты действия ферментов класса ADAR при заболеваниях человека. На рисунке изображено участие ферментов класса ADAR в развитии определенных патологий. Так, ADAR1 связан с защитой против вирусных инфекций и воспаления, развитием нескольких видов злокачественных опухолей, а также редактированием глутаматных рецепторов при нормальном развитии ЦНС. ADAR2 оказывает как положительный, так и отрицательный эффект на прогрессию опухоли, а его дефицит может вызывать различные заболевания ЦНС

Онкосупрессорные свойства ADAR2 вызывают особый интерес при исследовании глиобластом. ADAR2опосредованное редактирование фосфатазы CDC14B, ответственной за повреждение ДНК, может изменять клеточный цикл, в который вовлечены белки Skp2 / p21 / p27, и ингибировать рост глиобластомы [12].

Несмотря на накопленные к настоящему времени знания о ферментах ADAR и их участии в редактировании PHK, значение этого процесса на настоящий момент не во всех случаях определено. В основном, неясно, какие из событий редактирования управляют судьбой транскриптов, какие обеспечивают функциональную пластичность протеома, а какие представляют собой молекулярный шум. Известно, что ADAR действует на очень разнообразные субстраты, которых роднит только наличие двухцепочечной РНК: матричные, короткие и длинные некодирующие РНК, а также вирусные РНК. Масштаб этого явления начинают осознавать лишь в последнее время, с введением полногеномных исследований модификаций PHK [1], результаты которых требуют дальнейшего подтверждения на фунциональном уровне.

Таким образом, к настоящему времени известно, что активность ADAR1 связана с противовирусным ответом и управлением реакцией клеток на интерфероны 1-го типа. Имеется общее мнение, что эта активность оказывает провирусное воздействие, а в случае отсутствия вирусов подавляет нежелательный клеточный иммунитет (например, мутации в гене adar вызывают синдром Айкарди-
Гутьерес, сопровождающийся детским энцефалитом и интерферонопатией). Активность ADAR2, по некоторым данным, связана с регуляцией работы ЦНС, например, в виде возбуждающих стимулов активности (рис. 1).

В литературных источниках также представлены примеры событий редактирования РНК, которые могут играть решающую роль в развитии рака. Вероятно, в некоторой степени активность ADAR1 оказывает онкогенное действие. Отредактированный с помощью этого фермента белок AZIN1 представляет возможную терапевтическую мишень. Белок COG3 в отредактированной форме может выступать в качестве предиктивного маркера и влиять на ответ при раковой терапии [15]. Редактирование мРНК таких белков, как CDC14B, PODXL, GABRA3 и IGFBP7 ферментом ADAR2, вероятно, обладает онкосупрессорными свойствами [4].

\section{ВЫВОДЫ}

Из описанных выше примеров следует, что эволюционно древний механизм редактирования PHK ферментами ADAR отвечает за разные, пока не до конца изученные функции в процессе эмбрионального развития, особенно в центральной нервной системе. Меняется уровень редактирования многих транскриптов и в патологии, например, при нейродегенеративных заболеваниях и злокачественных опухолях. Требуются дальнейшие исследования механизмов воздействия редактирования PHK на процессы в клетках и тканях. Нужно отличить 
действительно значимые события такого редактирования от молекулярного шума. По мере накопления знаний необходимо выяснить, можно ли ферменты ADAR и продукты их реакции рассматривать в качестве прогностических и предиктивных биомаркеров, а также молекулярных мишеней для терапевтического воздействия.

\section{Литература}

1. Tan MH, Li Q, Shanmugam R, Piskol R, Kohler J, Young AN, et al. Dynamic landscape and regulation of RNA editing in mammals. Nature. 2017; (550): 249-54.

2. Basilio C, Wahba AJ, Lengyel P, Speyer JF, Ochoa S. Synthetic polynucleotides and the amino acid code. V Proc Natl Acad Sci USA. 1962; (48): 613-6.

3. Liscovitch-Brauer N, Alon S, Porath HT, Elstein B, Unger R, Ziv T, et al. Trade-off between Transcriptome Plasticity and Genome Evolution in Cephalopods. Cell. 2017; (169): 191-202.e11.

4. Gallo A, Vukic D, Michalík D, O'Connell MA, Keegan LP. ADAR RNA editing in human disease; more to it than meets the I. Hum Genet. 2017; (136): 1265-78.

5. Young PE, Kum Jew S, Buckland ME, Pamphlett R, Suter CM. Epigenetic differences between monozygotic twins discordant for amyotrophic lateral sclerosis (ALS) provide clues to disease pathogenesis. PLoS One. 2017; (12): e0182638.

6. Taylor DR, Puig M, Darnell MER, Mihalik K, Feinstone SM. New antiviral pathway that mediates hepatitis $\mathrm{C}$ virus replicon interferon sensitivity through ADAR1. J Virol. 2005; (79): 6291-8.

7. Suspène R, Petit V, Puyraimond-Zemmour D, Aynaud MM, Henry M, Guétard D, et al. Double-stranded RNA adenosine deaminase ADAR-1-induced hypermutated genomes among inactivated seasonal influenza and live attenuated measles virus vaccines. $J$ Virol. 2011; (85): 2458-62.
8. John L, Samuel CE. Induction of stress granules by interferon and down-regulation by the cellular RNA adenosine deaminase ADAR1. Virology. 2014; (454-455): 299-310.

9. Crow YJ. Aicardi-Goutières syndrome. Handb Clin Neurol. 2013; (113): 1629-35

10. Tomczak K, Czerwińska P, Wiznerowicz M. The Cancer Genome Atlas (TCGA): an immeasurable source of knowledge. Contemp Oncol (Poznan, Poland). 2015; (19): A68-77.

11. Peng X, Xu X, Wang Y, Hawke DH, Yu S, Han L, et al. A-to-I RNA Editing Contributes to Proteomic Diversity in Cancer. Cancer Cell. 2018; (33): 817-828.e7.

12. Galeano F, Rossetti C, Tomaselli S, Cifaldi L, Lezzerini M, Pezzullo M, et al. ADAR2-editing activity inhibits glioblastoma growth through the modulation of the CDC14B/Skp2/p21/p27 axis. Oncogene. 2013; (32): 998-1009.

13. Chen L, Li Y, Lin CH, Chan THM, Chow RKK, Song $Y$, et al. Recoding RNA editing of AZIN1 predisposes to hepatocellular carcinoma. Nat Med. 2013; (19): 209-16.

14. Han L, Diao L, Yu S, Xu X, Li J, Zhang R, et al. The Genomic Landscape and Clinical Relevance of A-to-I RNA Editing in Human Cancers. Cancer Cell. 2015; (28): 515-28.

15. Xu X, Wang $Y$, Liang $\mathrm{H}$. The role of A-to-I RNA editing in cancer development. Curr Opin Genet Dev. 2018; (48): 51-6.

\section{References}

1. Tan MH, Li Q, Shanmugam R, Piskol R, Kohler J, Young AN, et al. Dynamic landscape and regulation of RNA editing in mammals. Nature. 2017; (550): 249-54

2. Basilio C, Wahba AJ, Lengyel P, Speyer JF, Ochoa S. Synthetic polynucleotides and the amino acid code. $V$ Proc Natl Acad Sci USA. 1962; (48): 613-6.

3. Liscovitch-Brauer N, Alon S, Porath HT, Elstein B, Unger R, Ziv T, et al. Trade-off between Transcriptome Plasticity and Genome Evolution in Cephalopods. Cell. 2017; (169): 191-202.e11.

4. Gallo A, Vukic D, Michalík D, O'Connell MA, Keegan LP. ADAR RNA editing in human disease; more to it than meets the I. Hum Genet. 2017; (136): 1265-78.

5. Young PE, Kum Jew S, Buckland ME, Pamphlett R, Suter CM. Epigenetic differences between monozygotic twins discordant for amyotrophic lateral sclerosis (ALS) provide clues to disease pathogenesis. PLoS One. 2017; (12): e0182638.

6. Taylor DR, Puig M, Darnell MER, Mihalik K, Feinstone SM. New antiviral pathway that mediates hepatitis $C$ virus replicon interferon sensitivity through ADAR1. J Virol. 2005; (79): 6291-8.

7. Suspène R, Petit V, Puyraimond-Zemmour D, Aynaud MM, Henry M, Guétard D, et al. Double-stranded RNA adenosine deaminase ADAR-1-induced hypermutated genomes among inactivated seasonal influenza and live attenuated measles virus vaccines. $J$ Virol. 2011; (85): 2458-62.
8. John L, Samuel CE. Induction of stress granules by interferon and down-regulation by the cellular RNA adenosine deaminase ADAR1. Virology. 2014; (454-455): 299-310.

9. Crow YJ. Aicardi-Goutières syndrome. Handb Clin Neurol. 2013; (113): 1629-35.

10. Tomczak K, Czerwińska P, Wiznerowicz M. The Cancer Genome Atlas (TCGA): an immeasurable source of knowledge. Contemp Oncol (Poznan, Poland). 2015; (19): A68-77.

11. Peng X, Xu X, Wang Y, Hawke DH, Yu S, Han L, et al. A-to-I RNA Editing Contributes to Proteomic Diversity in Cancer. Cancer Cell. 2018; (33): 817-828.e7.

12. Galeano F, Rossetti $C$, Tomaselli S, Cifaldi L, Lezzerini M, Pezzullo M, et al. ADAR2-editing activity inhibits glioblastoma growth through the modulation of the CDC14B/Skp2/p21/p27 axis. Oncogene. 2013; (32): 998-1009.

13. Chen L, Li Y, Lin CH, Chan THM, Chow RKK, Song $Y$, et al. Recoding RNA editing of AZIN1 predisposes to hepatocellular carcinoma. Nat Med. 2013; (19): 209-16.

14. Han L, Diao L, Yu S, Xu X, Li J, Zhang R, et al. The Genomic Landscape and Clinical Relevance of A-to-I RNA Editing in Human Cancers. Cancer Cell. 2015; (28): 515-28.

15. $\mathrm{Xu} X$, Wang $\mathrm{Y}$, Liang $\mathrm{H}$. The role of A-to-I RNA editing in cancer development. Curr Opin Genet Dev. 2018; (48): 51-6. 